\title{
35. Body and speech as expression of inner states
}

1. Introduction

2. General concepts of German Expression Psychology

3. Selected authors

4. Relevance for current research

5. References

\section{Abstract}

This article provides a sketch of the theoretical framework of German Expression Psychology (GEP) and discusses the forms and functions of bodily and verbal types of communication that express inner states. Starting with a brief historical overview, we discuss general concepts of the German Expression Psychology framework, in particular with respect to the definition of expression, the relationship between expression and its subject, and the perception of expression. Within each of these areas special attention is given to the face, body and voice as indicators of inner states. Following this general overview of German Expression Psychology, we focus on the contribution of three selected authors, namely, Philipp Lersch, Paul Leyhausen and Egon Brunswik, who have been particularly influential in the field of German Expression Psychology. For Lersch, we consider the co-existential relationship between affect and expression, the detailed anatomical description of expressions, as well as the analysis of dynamic aspects of expressions. Leyhausen added an ethological perspective on expressions and perceptions. Here, we focus on the developmental aspects of expression and impression formation, and differentiate between phylogenetic and ontogenetic aspects of expression. Brunswik's Lens Model allows a separation between distal indicators on the part of the sender and proximal percepts on the part of the observer. Here, we discuss how such a model can be used to describe and analyze nonverbal communication on both the encoding and decoding side. Deriving from the presentation of all three authors, we outline the general relevance of German Expression Psychology for current research, specifically with respect to the definition and function of expressions and perceptions, and existing approaches to the study of verbal and nonverbal behavior.

\section{Introduction}

Since Darwin (1872), the concept of expression has played a central role in the psychological understanding of emotions. As in other domains, the field of expression research has undergone several changes and transformations. Interestingly, these conceptual and methodological shifts have been linked to different research traditions in Europe and the USA. German Expression Psychology as reviewed in this chapter encompasses all research on nonverbal behavior that has been performed by German-speaking expression psychologists (Asendorpf and Wallbott 1982). In this research vein, topics such as facial expression, gestures and body movements were active areas of inquiry and part of the curriculum in psychology at German universities until the sixties (see Scherer and Wallbott 1990). However, just like the study of emotions, which had lost its attraction in the past decades of psychological research, expression psychology 
soon literally disappeared from the field. The approach used by many traditional German Expression Psychology psychologists such as Lersch, Kirchhoff, Klages and Leonhard was criticized for being speculative and unscientific in nature. Many empirical psychologists rejected this type of philosophical and phenomenological analysis. As a result, German Expression Psychology disappeared at the end of the sixties and was replaced in the seventies by a new research domain called "nonverbal communication research." This new line of research, which was influenced primarily by American psychology, was driven by a research model based on systematic and objective measurement. With its development, a new generation of psychologists working on expressive behavior emerged in Germany and Europe, almost independently of the classic field of "expression psychology" (Asendorpf and Wallbott 1982).

The present paper aims to review important concepts and ideas of German Expression Psychology which no longer receive much attention but have contributed to our understanding of nonverbal communication. A complete overview of German Expression Psychology and its contribution for each channel of communication (face, body, voice) can be found in a series of special issues on German Expression Psychology by Asendorpf, Wallbott and Helfrich published in the Journal of Nonverbal Behavior in 1982 and 1986. In the present paper, therefore, an exhaustive description of German Expression Psychology will not be provided. Instead, following a short summary of German Expression Psychology based on the articles just referred to, we will focus on the contribution of three selected authors, namely Lersch, Leyhausen and Brunswik. Each of these authors has added his own definition and perspective to the field of expression psychology. Deriving from the description of the work of all three authors, we will outline the extent to which German Expression Psychology is still relevant for current research on nonverbal behavior.

\section{General concepts of German Expression Psychology}

German Expression Psychology represents one of the first research traditions to systematically investigate expressive behavior. In this tradition, the main focus was on the expression as an observable behavior or act. The emotion-eliciting processes were only rarely studied by experimental manipulation. Rather, contents of expressions were generally considered to be "permanent or transient psychic states, such as affective states, personality characteristics, such as 'temperaments' (Temperament), and (rarely) social attitudes" (Asendorpf and Wallbott 1982: 137). Expression was consequently a more fixed concept in which the expressive act with its observable features was the crucial research issue. Common to the definitions of expression was the notion of genuineness or spontaneity. Expressions were regarded mainly as externalizations of inner-psychic states or traits, and therefore spontaneous and genuine in nature (Asendorpf and Wallbott 1982).

The ultimate goal of expression psychology was to develop diagnostic tools. For this purpose, there were attempts to establish a lexicon or inventory of emotional expressions that assigned meaning to each type of expression (see Klages 1926; Lersch 1957, 1961). However, the procedures used were based mainly on case studies and personal observations. Moreover, the emphasis of many of these investigations lay in the subjective description of perceived cues and impression formation. The lack of objective measurement was particularly severe in research on facial expressions (Asendorpf 1982). 
For body movements, gait and gestures, measurement techniques ranged from subjective descriptions and judgments to more objective approaches (Wallbott 1982). However, even in the case of complex and demanding techniques (such as time-way graphs, light paths, and stereo photography), there was a tendency to interpret the captured data in subjective and evaluative terms (Scherer and Wallbott 1990). Similarly, for voice and speech, a distinction was drawn between a genetic, acoustic or auditory level and an impressionistic or phenomenological one. Most research interests, however, focused on the phenomenological approach with its holistically perceived qualities of spoken messages. In contrast, electro-acoustical methods of recording on the auditory level were treated with caution and considered useful only in combination with a holistic approach (Helfrich and Wallbott 1986).

Clearly, the focus of German Expression Psychology was not on the abstraction of single variables and their objective measurement but rather on the supposed meaning of expressions. Although an expressive act could have more than one meaning, the relationship between the expression and its subject was regarded rather as constant and invariant. In many cases, verbal and nonverbal phenomena were seen as indicative of individual characteristics such as affective states and personality attributes (Asendorpf and Wallbott 1982), German Expression Psychology thereby being diagnostic in its approach. This was particularly pronounced in the case of research on gait and gestures. Here, the primary interest was not in the expression of emotion, but more in the expression of character or personality itself (Wallbott 1982). In addition to the functional value of body movements, it was thought that valuable information about the person's character could be extracted. In consequence, research interests were mainly concerned with behavior characteristics and typological approaches to personality such as those suggested by Kretschmer: for example, pyknics, athletics and leptosomics (see Kretschmer 1940). A similar approach applied to research on voice and speech. Although objective views existed that treated vocal features merely as indicators of speech content, most studies adopted a subjective person-related view. That is, an association was made between expressive features and the underlying personality traits of the speaker. Research attempts consequently focused on the identification and interpretation of different speech types and vocal characteristics in relation to personality or by attributing certain traits by simply listening to the voice (Helfrich and Wallbott 1986).

The basis for such associative links between expression and personality were mainly semantic analogies. That is, the person-specific characteristics were inferred from a semantic description of the expression. In most cases, the meaning of the expression was derived by analogy from the function of the respective action (Asendorpf and Wallbott 1982). For example, eyelid droop has the function of diminishing the visual input from outside. By analogy, it follows that a person with lowered eyelids should have a passive and unfocused attitude towards the world (Lersch 1961). Unfortunately, operationalizations for "passive" and "unfocused" were seldom given. Moreover, such inference-by-analogy syllogisms were not subject to empirical research that included standardized tests. Such analogical-metaphorical conclusions, close to the concepts of naïve psychology, were responsible for much of the later criticism of German Expression Psychology as being unscientific and subjective in nature (Asendorpf and Wallbott 1982).

Within German Expression Psychology, concepts of expression and perception were highly interlinked. That is, no clear distinction was made between expression and 
impression. Rather, both concepts were seen as a gestalt - a holistic perceptual pattern. As with expression, conclusions were often drawn by analogy and not directly traceable (Asendorpf and Wallbott 1982). However, more explicit theories also existed that tried to determine the effects of specific behavioral cues on impression formation. This was particularly the case for research on the face. Here, the main focus of German Expression Psychology consisted of the perception and imitation of facial expressions (Asendorpf 1982). Specifically, the role of certain facial areas and components in evoking behavioral responses was of research interest. Such component studies consisted of the systematic variation of specific facial characteristics using schematized stimuli or drawings. Other experiments explored the relative contribution of static (physiognomic) and dynamic (pathognomic) cues, or facial and verbal cues in impression formation (Asendorpf 1982). A crucial concept was that of imitation in which the feelings experienced by the perceiver (due to the mimicry of the sender's expression) were thought to lead to the attribution of feelings to the sender. In order to describe this expression-impression process, constructs such as expression, perception and attribution were important. Although the focus was mainly on the perceived cues and their imitation, this approach was not far from Brunswik's Lens Model (see Asendorpf and Wallbott 1982; Brunswik 1956). Here also a distinction was made between externalization, perception and inference. In the Lens Model, a more fine-grained analysis was conducted with respect to the type of eliciting emotion, the cues expressed and the impressions formed. The majority of studies in German Expression Psychology failed to go to such a detailed and objective level of description and in consequence experimental designs were often unrepresentative with respect to their methodology.

\section{Selected authors}

In the following, we will focus on the concepts and theories of three authors influential in the field of German Expression Psychology; namely Phillipp Lersch, Paul Leyhausen, and Egon Brunswick.

\subsection{Philipp Lersch}

After obtaining a doctorate in German literature, Lersch studied psychology and philosophy under the supervision of Erich Becher, Moritz Geiger and Alex Pfänder. For Lersch (1961), defining expression required the distinction between inside and outside. According to him, contents of the outside world were perceived in a way that was meaningful to the inner state of the person. In this sense, expressions always contained a meaning that could be understood through interpretation of sensory signals of an inner state.

The relationship between expression and inner state (affect) was thought to be interdependent and co-existential. Both the sensory phenomenon as expressive signal and its mental contents were grounded in this co-existence. Lersch rejected the dualist view of body and inner state. For him, expression and affect were not connected in a causal way. Rather, he considered them to be two parts of the same process, together constituting a whole. The scream of terror, the blushing in shame, and the cries of mourning were all part of a psychophysical unity of the living mental body. Common to the definitions of expression was the notion of spontaneity which was highly regarded in the field of 
German Expression Psychology. Expressive acts were thought of as spontaneous signals of inner-psychic states. Given the continuous fluctuation of feelings and mental contents, expressive signals were proposed to be continuously changing. By this definition, Lersch distinguished spontaneous expressions from other expressive signals that were static or causal in their nature (e.g. hand-writing). The latter phenomena were not considered to be direct, but rather seen as traces of past expressive acts. A distinction was also drawn between physiognomic cues that were due to the morphological characteristics of the face and recurring expressive acts that had been solidified as a mimic trace in the face. Although Lersch's concept of expression included the notion of temporal continuity, the relationship between expression and inner state or personality trait was regarded as constant and permanent. Thus, variability in the meaning of expressions was restricted, and the role played by social and interpersonal factors was hardly considered.

An important facet of Lersch's approach was the analysis of the impressions (Eindrucksanalyse) people formed when viewing facial expressions. Given the fleeting nature of most expressions, he argued that the impressions formed would mostly be vague. That is, people would not be able to provide information about the basis on which they formed their impressions. Tracing these impressions back to their phenomenological roots was therefore seen as a crucial task in expression psychology. Specifically, it was felt that the objective basis of impressions should be made conscious. According to Lersch, such an approach would allow a differentiation between those impressions that were based on morphological characteristics of the face and those that were based on expressive acts of the individual. Lersch took great care in describing the changes in appearance of the upper and lower face based on an anatomicalphysiological analysis and provided a detailed anatomical overview of 19 different facial muscles and their involvement in various facial actions. For the upper face, he described actions of the eyes (i.e., eyelid raise, squinting, lids drooping, gazing) and the eyebrows (i.e., horizontal furrows, vertical furrows). For example, in squinting, the eye aperture is narrowed due to the contraction of two muscle innervations that are opposite to each other: the inner eye circle muscle and the eye cover fold. For the lower face, he described actions of the lips (e.g., lip pressing, open lips) and mouth corners (e.g., lip corner depressing, smiling). For example, in lip pressing, the lower lip is pressed against the upper lip, thereby narrowing the red parts of the lips and pinching them slightly inwards.

Although the anatomical basis of such expressive features was objectively determined, the ultimate goal was to define their diagnostic meaning. This went beyond the description of visible and anatomical changes in the face, aiming to determine the underlying psychological meaning of expressive acts. Which contents of the conscious mind are expressed? What is the psychological purpose of showing expressions? By answering those questions, Lersch aimed to specify the meaning of expressions as signals of inner states. Moreover, he speculated about their characterological sense and wanted to find out what certain behaviors meant with respect to the characteristics of the whole person. According to Lersch, squinting, for example, had the function of more consciously observing the world as well as protecting oneself from the perception of the outside world. Due to its dual nature, it was supposedly found in shy and dishonest people and in humans who feel guilty. Similarly, lip pressing was supposed to occur in states of determination, defiance, decisiveness, and distrust. Lersch speculated about regularities and rules according to which an expression could be explained. Using such 
an approach, he aimed to set up an inventory that assigned meaning to each type of expression. Such descriptions were highly subjective and influenced by semantic analogies as was common in the field of German Expression Psychology. Operationalizations for constructs such as dishonesty or guilt were seldom given. Moreover, such inferences were often based on personal observations and derived from the functional value of expressive acts.

In his article about the theory of facial expressions, Lersch (1957) proposed four laws for the occurrence of expressive acts. The law of organ function defined facial expressions as purposeful behavior specific to the function of a relevant organ within the body (e.g., disgust reaction). Expressions could also occur without experiencing a bodily reaction, but in the context of inner states that were similar to that experience (e.g., displeasure, reluctance, law of symbolic transference). According to the law of demonstrative accentuation, certain expressions occurred to amplify feelings and attitudes of social significance (i.e., lip pressing as a sign to demonstratively underline one's determination). The law of contrasting accentuation proposed that expressions of maximally different appearance were accompanied by inner states that were opposite to each other (i.e., smiling in laughter and lip corner depressing in melancholy). From these descriptions of the four laws, it becomes evident that some of them were based on Darwin's (1872) two principles of serviceable associated habits and of antithesis. However, Lersch did not argue for an exclusive evolutionary explanation of each law on its own, acknowledging that expressions could be understood by more than one law.

In his attempt to interpret expressive acts as signs of inner states, Lersch also paid attention to the dynamic configuration of facial expressions such as the intensity and the movement of expressions. According to him, these would provide greater depth of information in addition to the static configuration of facial displays. Lersch distinguished between two types of movement: round-fluent movements, which were characterized by smooth occurrence, no abrupt changes and slow offsets, and angular-stiff movements. In the latter, the expression started quickly and was held rigidly before abruptly returning to a neutral baseline. According to Lersch, such varying movements could apply to facial displays (e.g., laughing), as well as to actions of the eyes and the head. Their meaning was thought to be crucial for understanding both the inner state of the person and possible action intentions towards the outer world. Although the interpretation of movement characteristics was far from being objective and was biased by typological approaches (e.g., Kretschmer's 1940 cyclothymes and schizothymes), important aspects of the nature of the underlying emotion were addressed. In this context, first attempts were made at explaining angular-stiff movements as signs of an inhibitory or voluntary act, and round-fluent motions as signs of an emotionally genuine act.

\subsection{Paul Leyhausen}

Paul Leyhausen, a student of Konrad Lorenz, performed extensive behavioral studies on several species, most commonly felines (see Peters 2000). He was convinced that an understanding of bodily expressions in humans could only be achieved using a comparative approach. By focusing on the interaction between genetically encoded origins of behaviors and experience and learning, Leyhausen emphasized notions that are still popular in present approaches to nonverbal behavior that are at the intersection of biological psychology, evolutionary psychology, and social neuroscience. One of the key 
elements in Leyhausen's arguments was the notion that expression and impression developed, to a certain degree, independently of one another and that their relationship was then shaped by the evolutionary pressures that social communication put on the respective systems (e.g., Leyhausen 1967). Specifically, he argued that the origin of expression was phylogenetically much earlier than the development and the genetic transmission of perceptual mechanisms that would be able to respond to expression. This notion offers explanations for certain (mis-)communication processes that are relevant for any current researcher interested in the communication of affect and intent. Leyhausen saw the possibility of predicting future behavior and adapting/reacting accordingly as the most important function of the communication process.

Leyhausen was peculiar in holding the assumption that expression refers to behavioral manifestations of action tendencies that do not correspond to the currently predominant behavior but that reflect competing processes. Thus, the expression was considered to be the blend of two or more conflicting behaviors or behavioral tendencies. Take the example of the arching of a cat's back in an aggressive context. Darwin interpreted this expression as an attempt to increase its size following the principle of antithesis (appear big when aggressive and small when submissive; see Darwin 1872: 56 and Figure 8: 58). However, following Lorenz's analysis of dog behavior, Leyhausen (1956, cited in 1967) demonstrated that the cat's arched back is more likely to be the consequence of a co-activation of two behavioral tendencies - flight and fight in this context - and only appears as a gesture of threat due to subjective human interpretation. Nonetheless, sometimes behaviors can be observed that do not seem to serve a purpose under conditions of competing action tendencies. Leyhausen argued that when it was impossible to follow any of these action tendencies, displacement activities (Übersprungshandlungen) could occur. A chicken in a fight or flight situation might start picking on the ground as if there were food. Humans might scratch their head when in behavioral conflict. Such behaviors would have been difficult for Darwin to explain using his three principles guiding the origins of expressions.

When addressing the issue of the impression, Darwin believed that experiences during one's lifetime could somehow be transmitted to the next generation, not unlike the mechanisms that Jean Baptiste Lamarck proposed (see also Cornelius 1996). This left various possibilities open concerning the development of impression. Leyhausen in turn benefited from knowledge of genetic mechanisms that were unavailable at the time of Darwin. He was able to reject Lamarckian transmission of experience and in turn focus on an evolutionary analysis, considering how impression mechanisms might have evolved and what the features of such mechanisms would be. This included the complex relationship of genotype and phenotype and features such as the stability or the variance of features in a given population in a given environment. A central feature of the genetically transmitted capacity for impression relates to the concept of the innate releasing mechanism (IRM). Based on studies of several species, Leyhausen argued that different individual aspects capable of triggering an innate releasing mechanism follow an additive logic, rather than pattern (Gestalt) principles. This is an important assumption because it opens doors for the strategic control of an interaction partner's innate releasing mechanism to achieve certain (social) goals (see also Fridlund 1994). Interestingly, in his analysis of communication in humans, Leyhausen considered aspects including fashion or stylized behaviors, such as mannerisms of speech or gesture, as well as behavioral traces, such as writing. 
Leyhausen strongly emphasized the need for comparative research, citing the long time period that must have been required for impression processes to evolve. He rejected views that focused only on humans and consequential fallacies, such as the confusion of homologies and analogies in the analysis of morphological structures or behaviors. In analyzing the communication process Leyhausen cast a wide net, considering behaviors of species as simple as protozoa (paramecia), ticks, or fish, as precursors to flexible impression and recognition mechanisms in humans. Of particular interest was his distinction - in higher organisms only - of "angeborenes Ausdruckserfassen," or Eindrucksfähigkeit on the one hand and "erworbenes Ausdruckserfassen," or Ausdrucksverstehen on the other. He referred to an innate grasp of expression as the capacity for impression and the acquired grasp of expression as understanding of expression. The use of the German term erfassen, which can literally be translated as 'grasping,' proves to be a particularly felicitous choice of words. Contemporary advances concerning the role of a mirror system in the pre-motor cortex (e.g., Rizzolatti and Craighero 2004) that may play a considerable role in the communication of affect and intention (see also Kappas and Descôteaux 2003) could indeed have more to do with grasping than thinking. In other words, there may be a more physical, action-oriented sense of the expression of other individuals rather than a mental construct such as matching a schema. Such notions go back to Lipps' theory of empathy and feature strongly in expression psychology (e.g., Lersch 1940 and Rothacker 1941, cited in Leyhausen 1967).

\subsection{Egon Brunswik}

Egon Brunswik was an assistant in Karl Bühler's (for a survey of Karl Bühler's theory of language, see Müller this volume) Psychological Institute (and a fellow-student of Konrad Lorenz), and received his $\mathrm{PhD}$ in 1927. In 1933, he met Edward C. Tolman in Vienna, and in 1935/1936 he received a Rockefeller fellowship enabling him to visit the University of California. He remained at Berkeley where he became an assistant professor of psychology in 1937 and a full professor in 1947. Brunswik $(1952,1956)$ formulated a number of theoretical and methodological principles with regard to the study of perception. He applied these principles to a range of phenomena including perceptual constancies and illusions and also to the attribution of psychological traits based on observation of the exterior of an individual. With respect to the concept of expression, Brunswik conducted only one study on the relationship between facial features of schematic drawings and a series of impression characteristics (mood, age, character, likeability, beauty, intelligence, energy; Brunswik and Reiter 1937, reprinted in Brunswik 1956). However, his methodological and theoretical framework has important implications for studying body and speech as expression of inner states. These implications were further highlighted by Scherer $(1978,2003)$, who proposed a modified version of Brunswik's Lens Model for research into non-verbal communication, in particular vocal communication of emotions.

In his Lens Model framework, Brunswik defined two main methodological and theoretical concepts - representative design and ecological validity respectively. Brunswik argued that psychological processes are adapted in a Darwinian sense to the environments in which they function (Dhami, Hertwig, and Hoffrage 2004). He proposed the method of representative design to capture these processes by sampling random stimuli from the environment or creating stimuli in which environmental properties are 
preserved. He criticized classical methods of experimental design for applying the demands of representativeness to the number of subjects but not to the number of objects (stimuli). Furthermore, he questioned the feasibility of experimental designs that select and isolate one or a few independent variables that are varied systematically whilst extraneous variables are held constant. In his view, the concept of representativeness is fundamental to generalization.

Brunswik's methodological principles were closely entwined with his theoretical outlook. Brunswik introduced the term ecological validity to indicate the degree of correlation between a proximal (e.g., retinal) cue and the distal (e.g., object) variable to which it is related. For example, in a perceptual task, ecological validity refers to the objectively measured correlation between, say, vertical position and size of an object (larger objects tend to be higher up in the visual field) over a series of situations. Or, in the domain of emotional expressions, one may compare the ecological validity of the cue "smiling" with the cue "reported happiness" as indicators of a person-object's emotional state. An important aspect of Brunswik's approach was his conviction that the environment to which an organism must adapt cannot be perfectly predicted from the proximal cues. A particular distal stimulus does not always imply specific proximal effects and vice versa. Proximal cues are only probabilistic indicators of a distal variable. The proximal cues are themselves interrelated, thus introducing redundancy into the environment.

Scherer $(1978,2003)$ has suggested modeling the relationship between emotions and expressive cues in a Brunswikian perspective. In this approach, the relationship between the underlying emotion and the expressive cues is probabilistic and many redundant cues are potentially available for both the expression and communication of emotion. Brunswik would probably question the current dominance of "modern" discrete emotion theories as represented by Ekman, Izard, and their respective collaborators (e.g., Ekman 1992; Izard 1991). Discrete emotion theorists claim that there are only a limited number of fundamental or basic emotions and that for each of these there exists a prototypical, innate, and universal expression pattern. In this basic emotion view, the association is deterministic and only allows minor variations (e.g. a motor program might be carried out only partially). In the Brunswikian probabilistic view, several expressive cues will be related independently to the emotional reaction, each with a defined probability. On different occasions, under different circumstances, different combinations of cues might be used to express the same emotion. The extended lens model integrates the study of the production (expression) and of the perception (impression) of emotional expressions.

In Scherer's model (see Scherer 2003, Figure 1: 229), the internal states - in this case, the emotions - are exteriorized in the form of distal indicators corresponding, in the case of vocal communication, to the acoustic characteristics of the voice. The notion of externalization covers both intentional communication of internal states and involuntary behavioral and physiological reactions. At the operational level, the internal states are represented by criterion values and the distal indicators by indicator values. These distal indicators are represented proximally by percepts which are the result of perceptual processing on the part of the observer. These percepts can be evaluated by perceptual judgments expressed as scores on psychophysical scales or dimensions. The correlations between indicator values and perceptual judgments are designated by the term representation coefficient, and indicate the degree of precision of the projection 
of distal indicators in the perceptual space of the individual. The attribution of a state is the result of inferential processes based on perception of the distal indicators. These attributions can be evaluated by obtaining new judgments on psychological dimensions from observers. The correlations between perceptual judgments and attributions are represented in the model by utilization coefficients which provide a measure of the utilization (or the weighting) of each index that is perceived when a state is inferred. The accuracy of these attributions in relation to the objectively observed state of the individual is defined at an operational level by the correlation between criterion values and attributions (coefficients of accuracy).

It is important to keep in mind that an emotion may be reliably attributed to a facial or a vocal display despite this emotion not being present in the sender. Conversely, when receivers cannot reliably attribute emotions to senders, this does not demonstrate that senders do not express emotions. Such an imperfect relationship between the encoding process and the attribution process has been demonstrated by Hess and Kleck (1994) using dynamic facial expressions, either posed or elicited by affectively evocative materials. Subjects were able to accurately report the cues they employed in assessing the perceived spontaneity or deliberateness of expressions. However, these cues were not always valid determinants of posed and spontaneous expressions. In fact, participants were relatively poor at identifying expressions of the two types, and this low discrimination accuracy was found to be a result of the consistent use of these invalid cues. Reynolds and Gifford (2001) reported a similar observation for the expression and perception of intelligence in nonverbal displays. They showed that intelligence, as measured by a test, was correlated with a few nonverbal cues that could be observed and measured in video recordings. Participants who were requested to rate intelligence on the basis of those videos were relatively consistent in using another set of cues to make inferences about intelligence. However, their ratings were not influenced by the cues that were related to the intelligence scores, and they didn't make accurate inferences.

\section{Relevance for current research}

German Expression Psychology has contributed important concepts and ideas to the study of nonverbal communication. These often neglected aspects of German Expression Psychology are of crucial interest for today's research on the face, body and voice. The impact of Lersch's work certainly consisted in the careful description of changes of appearance in the face. Although such descriptions were often incomplete and contaminated with inferences about meaning (see Ekman 1979), they contributed to more extensive methods of measuring facial behavior developed later. One of the currently most widely used descriptive systems is the Facial Action Coding System (FACS) by Ekman and Friesen (1978) (For an account of Facial Action Coding System, see Waller and Smith Pasqualini this volume). It describes all possible visually distinguishable facial movements (Ekman and Friesen 1982b). Similarly to Lersch's approach, it is based on the anatomy of facial action. However, no inferences are made about the meanings of facial behavior, and measurements are based on non-inferential terms (Ekman 1982). The Facial Action Coding System also allows for the analysis of dynamic phases such as onset, apex and offset time. Lersch was certainly one of the first researchers who pointed to the importance of dynamic aspects in facial expressions. His idea that facial motion carries crucial information about the person and the 
person's expression can be found in much recent research on facial dynamics (i.e., Ambadar, Schooler, and Cohn 2005; Bassili 1978; Wehrle, Kaiser, Schmidt, et al. 2000). Particularly, the distinction between angular-stiff and round-fluent movement has relevance for today's study of fake and genuine expressions (see Ekman and Friesen 1982a; Krumhuber and Kappas 2005; Krumhuber, Manstead, and Kappas 2007).

Leyhausen argued for a clear separation between the study and the analysis of expression and impression. In this respect, his approach was not far from Brunswik's concept (e.g., Brunswik 1956; see also Kappas, Hess, and Scherer 1991). However, the ethological approach Leyhausen represents has pointed to a certain asymmetry between the origins and, in consequence, the plasticity of expression and impression processes in humans. The discovery of a mirror system in the brain (e.g., Rizzolatti and Craighero 2004) and systematic studies on imitative behavior (e.g., in the shape of the Chameleon effect, e.g., Chartrand and Bargh 1999) are concordant with Leyhausen's analysis that the impressions gathered from bodily expressions are much less flexible than the expressions themselves. Research by Todorov and his colleagues has demonstrated how dramatically fast impressions are arrived at, with individuals showing great confidence in literally fractions of seconds (Todorov, Mandisodza, Goren, et al. 2005; Willis and Todorov 2006). These findings suggest rapid automatic effects that are consistent with the type of mechanisms postulated by Leyhausen. In other words, this is not about what faces or bodily expressions really say, but what people think they say. This can be attributed to our evolutionary past, where it was useful to act quickly in response to certain signs. A closer analysis of Leyhausen's predictions might be highly productive for furthering our understanding of "old questions" about issues such as miscommunication, misattribution, or insensitivity to deception based on expressive cues. These questions are currently difficult to answer when the attempt is based on an analysis that centers only on humans in the here and now and does not take phylogenetic trajectories into account. Leyhausen's work may also prove useful for current and developing questions linked to computer-mediated communication, for instance what level of realism is really needed for artificial entities, such as agents, avatars, or embodied robots.

Brunswik's lens model was quick to be used and gain support at the time of its appearance, particularly by Hammond (1955), who remains to this day a strong defender of this paradigm. Hammond's initial application of the lens model was in the area of judgment analysis (or decision making), using the paradigm to analyze clinical (diagnostic) judgments by psychiatrists and psychologists. Holzworth (2001) has presented a brief review of the research regarding analysis of judgments from a Brunswikian perspective. In this review, the author finds that the value to be ascribed to analysis of judgments quickly became oriented towards problems of interpersonal perception. In this area, Albright and Malloy (2001) go as far as to state: "All research on interpersonal perception is Brunswikian, because the use of real people as targets of judgment invokes the principle of representative covariation. Because Brunswik was the first to conduct a theoretically based and comprehensive [...] study of social perception, he was the originator of the interpersonal approach to social perception research" (Albright and Malloy 2001: 330-331). Brunswik was certainly ahead of his time and was criticized by gestalt psychologists (e.g. Kurt Lewin) as well as by behaviorists, experimental psychologists and statisticians. However, in the present day, Brunswik's emphasis on the importance of the environment is reflected in the increasing development of "ecological psychology," as illustrated by the work of Barker (1968). 
German Expression Psychology remained an active research area until the sixties and devoted much interest to what is now termed nonverbal communication. Unfortunately, its concepts and theories are often overlooked in today's research. From the presentation of three selected authors within the field of German Expression Psychology, namely Lersch, Leyhausen and Brunswik, we wanted to demonstrate how rich and wide-ranging their ideas have been. These ideas do not only reject the notion of discrete prototypes of emotional expressions but also highlight the complexities in impression formation and management. German Expression Psychology therefore has an important status in providing the framework for much later empirical work on nonverbal behavior. In this sense, it may be an ancestor of modern nonverbal communication research, but it continues to contribute to today's perspectives on bodily and verbal forms of behavior to express inner states.

\section{References}

Albright, Linda and Thomas E. Malloy 2001. Brunswik's theoretical and methodological contributions to research in interpersonal perception. In: Kenneth R. Hammond and Thomas R. Stewart (eds.), The Essential Brunswik: Beginnings, Explications, Applications, 328-331. New York: Oxford University Press.

Ambadar, Zara, Jonathan W. Schooler and Jeffrey F. Cohn 2005. Deciphering the enigmatic face: The importance of facial dynamics in interpreting subtle facial expressions. Psychological Science 16: 403-410.

Asendorpf, Jens 1982. Contributions of the German "Expression Psychology" to nonverbal communication research, Part II: The face. Journal of Nonverbal Behavior 6: 199-219.

Asendorpf, Jens and Harald G. Wallbott 1982. Contributions of the German "Expression Psychology" to nonverbal communication research, Part I: Theories and concepts. Journal of Nonverbal Behavior 6: 135-147.

Barker, Roger G. 1968. Ecological Psychology: Concepts and Methods for Studying the Environment of Human Behavior. Stanford, CA: Stanford University Press.

Bassili, John N. 1978. Facial motion in the perception of faces and of emotional expression. Journal of Experimental Psychology: Human Perception and Performance 4: 373-379.

Brunswik, Egon 1952. The Conceptual Framework of Psychology. International Encyclopedia of Unified Science, Volume 1, Number 10. Chicago: University of Chicago Press.

Brunswik, Egon 1956. Perception and the Representative Design of Psychological Experiments. Berkeley: University of California Press.

Brunswik, Emil and Lotte Reiter 1937. Eindrucks-Charaktere schematisierter Gesichter. Zeitschrift für Psychologie 142: 67-134.

Chartrand, Tanya L. and John A. Bargh 1999. The chameleon effect: The perception-behavior link and social interaction. Journal of Personality and Social Psychology 76: 893-910.

Cornelius, Randolph. R. 1996. The Science of Emotion. Upper Saddle River, NJ: Prentice Hall.

Darwin, Charles 1872. The Expression of the Emotions in Man and Animals. London: John Murray.

Dhami, Mandeep, Ralph Hertwig and Ulrich Hoffrage 2004. The role of representative design in an ecological approach to cognition. Psychological Bulletin 130: 959-988.

Ekman, Paul 1979. Non-verbal and verbal rituals in interaction. In: Mario von Cranach, Klaus Foppa, Wolfgang Lepenies and Detlev Ploog (eds.), Human Ethology: Claims and Limits of a New Discipline, 169-202. Cambridge: Cambridge University Press.

Ekman, Paul 1982. Methods for measuring facial action. In: Klaus R. Scherer and Paul Ekman (eds.), Handbook of Methods in Nonverbal Behavior Research, 45-90. Cambridge: Cambridge University Press.

Ekman, Paul 1992. Facial expressions of emotion: New findings, new questions. Psychological Science 3: 34-38. 
Ekman, Paul and Wallace V. Friesen 1978. The Facial Action Coding System. Palo Alto, CA: Consulting Psychologists Press.

Ekman, Paul and Wallace V. Friesen 1982a. Felt, false and miserable smiles. Journal of Nonverbal Behavior 6: 238-252.

Ekman, Paul and Wallace V. Friesen 1982b. Measuring facial movement with the Facial Action Coding System. In: Paul Ekman (ed.), Emotion in the Human Face. 2nd edition, 178-211. Cambridge: Cambridge University Press; Paris: Editions de la Maison des Sciences de l'Homme.

Fridlund, Alan J. 1994. Human Facial Expression: An Evolutionary View. San Diego, CA: Academic Press.

Hammond, Kenneth R. 1955. Probabilistic functioning and the clinical method. Psychological Review 62: 255-262.

Helfrich, Hede and Harald G. Wallbott 1986. Contributions of the German "Expression Psychology" to nonverbal communication research, Part IV, The voice. Journal of Nonverbal Behavior 10: $187-204$.

Hess, Ursula and Robert E. Kleck 1994. The cues decoders use in attempting to differentiate emotion-elicited and posed facial expressions. European Journal of Psychology 24: 367-381.

Holzworth, R. James 2001. Judgment analysis. In: Kenneth R. Hammond and Thomas R. Stewart (eds.), The Essential Brunswik: Beginnings, Explications, Applications, 324-327. New York: Oxford University Press.

Izard, Carroll E. 1991. The Psychology of Emotions. New York: Plenum Press.

Kappas, Arvid and Jean Descôteaux 2003. Of butterflies and roaring thunder: Nonverbal communication in interaction and regulation of emotion. In: Pierre Philippot, Erik J. Coats and Robert S. Feldman (eds.), Nonverbal Behavior in Clinical Settings, 45-74. New York: Oxford University Press.

Kappas, Arvid, Ursula Hess and Klaus R. Scherer 1991. Voice and emotion. In: Robert S. Feldman and Bernard Rimé (eds.), Fundamentals of Nonverbal Behavior, 200-238. Cambridge: Cambridge University Press.

Klages, Ludwig 1926. Grundlagen der Charakterkunde. Leipzig: J. A. Barth.

Kretschmer, Ernst 1940. Körperbau und Charakter. Berlin: J. Springer.

Krumhuber, Eva and Arvid Kappas 2005. Moving smiles: The role of dynamic components for the perception of the genuineness of smiles. Journal of Nonverbal Behavior 29: 3-24.

Krumhuber, Eva, Antony S. R. Manstead and Arvid Kappas 2007. Temporal aspects of facial displays in person and expression perception. The effects of smile dynamics, head-tilt and gender. Journal of Nonverbal Behavior 31: 39-56.

Lersch, Philipp 1940. Seele und Welt. Leipzig: J. A. Barth.

Lersch, Philipp 1957. Zur Theorie des mimischen Ausdrucks. Zeitschrift für Experimentelle und Angewandte Psychologie 4: 409-419.

Lersch, Philipp 1961. Gesicht und Seele. Munich: E. Reinhardt.

Leyhausen, Paul 1956. Verhaltensstudien an Katzen. Zeitschrift für Tierpsycholologie, Beiheft 2.

Leyhausen, Paul 1967. Biologie von Ausdruck und Eindruck. Psychologische Forschung 31: 113-227.

Müller, Cornelia this volume. Gestures as a medium of expression: The linguistic potential of gestures. In: Cornelia Müller, Alan Cienki, Ellen Fricke, Silva H. Ladewig, David McNeill and Sedinha Teßendorf (eds.), Body-Language-Communication: An International Handbook on Multimodality in Human Interaction. (Handbooks of Linguistics and Communication Science 38.1.) Berlin: De Gruyter Mouton.

Peters, Gustav 2000. Nachruf: Paul Leyhausen (1916-1998). Bonner Zoologische Beiträge 49: 179-189.

Reynolds, D'Arcy J. and Robert Gifford 2001. The sounds and sights of intelligence: A lens model channel analysis. Personality and Social Psychology Bulletin 27: 187-200.

Rizzolatti, Buccino G. and Fadiga L. Craighero 2004. The mirror-neuron system. Annual Review of Neuroscience 27: 169-192.

Rothacker, Erich 1941. Die Schichten der Persönlichkeit (2. Auflage). Leipzig: J. A. Barth. 
Scherer, Klaus R. 1978. Personality inference from voice quality: The loud voice of extroversion. European Journal of Social Psychology 8: 467-487.

Scherer, Klaus R. 2003. Vocal communication of emotion: A review of research paradigms. Speech Communication 40: 227-256.

Scherer, Klaus R. and Harald G. Wallbott 1990. Ausdruck von Emotionen. In: Klaus R. Scherer (ed.), Enzyklopädie der Psychologie. Band C/IV/3 Psychologie der Emotion, 345-422. Göttingen: Hogrefe.

Todorov, Alex, Anesu N. Mandisodza, Amir Goren and Crystal C. Hall 2005. Inferences of competence from faces predict election outcomes. Science 308: 1623-1626.

Wallbott, Harald G. 1982. Contributions of the German "Expression Psychology" to nonverbal communication research. Part III: Gait, gestures, and body movement. Journal of Nonverbal Behavior 7: 20-32.

Waller, Bridget and Marcia Smith Pasqualini this volume. Analysing facial expression using Facial Action Coding Systems (FACS). In: Cornelia Müller, Alan Cienki, Ellen Fricke, Silva H. Ladewig, David McNeill and Sedinha Teßendorf (eds.), Body-Language-Communication: An International Handbook on Multimodality in Human Interaction. (Handbooks of Linguistics and Communication Science 38.1.) Berlin: De Gruyter Mouton.

Wehrle, Thomas, Susanne Kaiser, Susanne Schmidt and Klaus R. Scherer 2000. Studying the dynamics of emotional expression using synthesized facial muscle movements. Journal of Personality and Social Psychology 78: 105-119.

Willis, Janine and Alex Todorov 2006. First impressions: Making up your mind after $100 \mathrm{~ms}$ exposure to a face. Psychological Science 17: 592-598.

Eva Krumhuber, Bremen, Germany

Susanne Kaiser, Geneva, Switzerland

Kappas Arvid, Bremen, Germany

Klaus R. Scherer, Geneva, Switzerland

\section{Fused Bodies: On the interrelatedness of cognition and interaction}

1. Introduction

2. Theoretical background

3. Conversation Analysis as method for doing Fused Bodies research

4. Cognition and Fused Bodies

5. Empirical evidence

6. References

\section{Abstract}

This chapter introduces the Fused Bodies (FB) approach to sense-making in social interaction. Using ethnographic observation and microanalyses of naturally occurring social interaction as its empirical basis, Fused Bodies focuses on sense-making in face-to-face encounters as the integrated whole of interactionally relevant, mutually oriented-to body movements at any given time during the interaction. Fused Bodies emphasizes that interactionally consequential body movements are more than just "behavior"; they 